\title{
Employee Turnover in the Business Process Outsourcing Industry in India
}

\author{
Aruna Ranganathan \\ Cornell University \\ Sarosh Kuruvilla \\ Cornell University
}

\section{ABSTRACT}

In this chapter, we explore the problem of high turnover in the high-tech BPO sector in India, where relatively well-educated employees are performing a variety of primarily low skill, low cost jobs. We highlight the various approaches employers are taking to solve the turnover problem. As we will argue, some of these strategies are fairly traditional, focusing on various instrumental incentives to promote employee retention, while some others are new and rather radical, particularly the articulation of an organization al and work culture tailor-made for the particular demographic profile of BPO employees: young, upper middle class, well-educated graduates. Based on anecdotal evidence and interviews with industry personnel, we sense some ambiguity regarding the effectiveness of these strategies. We argue that this ambiguity is a function of (a) the recent and rapid growth of the industry and the fact that firms are experimenting with a whole variety of retention strategies, and (b) the inability of firms to develop an integrated organizational culture that permits a focus on both longer term organizational performance, as well as retention.

\section{INTRODUCTION}

The IT (information technology) industry in India (commonly referred to as the outsourcing industry) is touted as being crucial to the country's economy. The industry has grown its revenues tenfold in the past decade, from U.S. \$4.8 billion in 1997-98 to U.S. \$47.8 billion in 2006-07. While it currently (2006) contributes only 5.4\% of India's GDP, this figure is expected to rise to $12.3 \%$ by 2012 (NASSCOM, 2007). Thus, the IT industry is expected to be a key driver of India's economic development via its contribution to GDP growth, employment growth, and poverty alleviation (Srinivasan, 2006).

There are three main segments in the IT industry: IT services and software, business process outsourcing (BPO), and hardware (NASSCOM, 2005). Though IT services and software accounts for the bulk of the industry at present, this segment has matured to some extent. On the contrary, the BPO sector is newer and is experiencing explosive growth. Projections indicate that the BPO sector will substantially overtake the software sector in value by 2012, other things being equal (Knowledge @Wharton, 2004b). And it is the BPO industry that has earned India the reputation of being the outsourcing capital of the world. Further, consolidation in the industry has resulted in several large software firms (e.g., Infosys, Wipro, and IBM) starting or buying out BPO units, thus blurring the distinction between software and BPO. We focus exclusively on the BPO sector in this chapter.

Although low costs and a seemingly endless supply of skilled human resources have been the key to India's leadership role in software and business process outsourcing, we argue in this chapter that continued growth of the BPO sector is contingent on it overcoming its biggest human resources problem (i.e., high turnover, which is posing a serious threat to growth and profitability in this sector ${ }^{a}$ ). Average turnover rates in the industry range from $25-40 \%$ (NASSCOM, 2005), imposing a significant cost on firms as they attempt to replace $40 \%$ of their employees per year in a very competitive labor market. Thus, despite possessing one of the world's 
largest supplies of skilled manpower, there is a desperate shortage of people in the industry.

Our goal in this chapter is modest, for example, to understand the causes and consequences of high turnover in the industry, and to document the variety of ways in which human resource departments in the BPO industry are attempting to address the critical issue of employee retention. In an industry where costs are a key source of comparative advantage, paying higher salaries to retain employees is self-defeating, as it threatens the longer-term viability of the industry. As it is, salary growth rates of $15-20 \%$ a year over the last few years has resulted in the movement of BPO jobs from India to China and other locations. Thus, BPO firms have to find other means of employee retention.

This situation therefore presents an interesting case study of a unique management problem, for example, the management of relatively well- educated employees in the high-tech sector who are doing a variety of primarily low skill, low cost jobs (although there is a growing high skills based research process outsourcing sector in India as well). Our study, based on interviews and participant observation of the BPO industry in India during 2005-2006, suggests that employers are experimenting with a variety of strategies to combat the turnover problem. As we will argue, some of these strategies are fairly traditional, focusing on various instrumental incentives to promote employee retention, while some others are new and rather radical, particularly the articulation of an organizational and work culture tailor-made for the particular demographic profile of BPO employees: young, upper middle class, welleducated graduates.

In the next section, we provide a (very) brief overview of the BPO sector in India. Thereafter, we discuss the nature and causes of turnover in the industry. We then describe various human resource (HR) strategies that companies are implementing in attempts to retain their employees. In the final section (although we do not yet have clear empirical evidence on which of the HR strategies are successful), we discuss these initiatives against the broader research background of turnover and organizational culture.

\section{THE BPO SECTOR IN INDIA}

There were various catalysts that led to the boom in business process outsourcing in India in the mid-1990s (see Dossani and Kenney, 2003 for a comprehensive discussion). The growth of the BPO industry capitalized on India's reputation as a software services provider, a reputation that first developed during the $\mathrm{Y} 2 \mathrm{~K}$ crisis. This reputation, alongside a large English speaking workforce and low costs (Indian costs are about $20 \%$ of U.S. costs in business processes), coupled with the time differences (India works while the U.S. sleeps), resulted in the establishment of call centers and back office services. The pioneering efforts of some MNCs in attempting to re-engineer business processes for cost savings paved the way for many others to outsource to India. Specifically, General Electric, American Express, and British Airways were quick to capitalize on the huge salary cost differentials between similarly trained employees in India and the United States. These MNCs also demonstrated that relocation could be undertaken with minimum disruption. And improvements in the enabling environment- notably the availability of telecommunications bandwidth at increasingly lower rates, the ability to digitize documents, and the usage of standard software platforms in corporate information systems - played a key role too.

Table 1 provides an overview of the BPO sector in India. While the $\$ 7$ billion sector currently accounts for only $23.8 \%$ of the total IT industry revenue, it has seen an average growth rate greater than 55\% during the $2000-2005$ period. It is this dramatic growth rate, its relatively high contribution to exports and the accompanying escalating employment potential that has raised the possibility that this sector will be the most important "development engine" for India.

India has a dominant position in the global market for offshore outsourcing, expected to account for $51 \%$ of the global aggregate by 2008 (NASSCOM, 2005). This market share growth is driven largely by India's numerous advantages (costs and availability of skilled manpower), including the newly acquired reputation of Indian firms' ability to "ramp-up" operations quickly based on demand. Indian 
also benefits from an English language advantage given that the U.S. and the U.S. are the predominant adopters of offshoring. Consulting firms such as AT Kearney rank India as the most favorable location for BPO activities in the world (see the data in Table 2) and highlight India's advantages in both com pen sat ion costs and skills.

Currently, there are over 400 large BPO firms in India (DTA Consultants, 2004), and this number is growing. Within the BPO segment, there are two kinds of firms - captives and third party firms. Captives are fully owned by major MNCs (e.g., Dell, GE Capital, EDS, HP) and provide business process services only to their owners. Third party firms (both Indian-owned and foreign-owned) provide BPO services to any client, and normally service a large number of clients simultaneously. Table 3 lists notable firms in both categories. Captives thus have a relatively stable market because their fortunes increase or decrease strictly based on their parent company's fortunes. Third party firms, on the other hand, are dependent on securing contracts with a variety of clients, and thus face a higher degree of uncertainty, which we argue will impact their ability to introduce policies to retain employees. Some captives such as GECIS (previously owned by GE) have now become third party firms. Further, the industry is undergoing a bout of consolidation, with large software firms (e.g., Infosys, 1BM, Wipro, and TCS) entering the business process outsourcing industry.

\section{Table 1. Overview of BPO sector in India}

\begin{tabular}{|c|c|c|c|c|c|}
\hline Year & $\begin{array}{l}\text { Total IT Industry Value } \\
\text { (U.S.S billion) }\end{array}$ & $\begin{array}{l}\text { BPO Segment Value } \\
\text { (U.S.S billions) }\end{array}$ & $\begin{array}{l}\text { BPO Exports } \\
\text { (U.S.S billion) }\end{array}$ & $\begin{array}{l}\text { Growth Rate of } \\
\text { BPO Segment }\end{array}$ & $\begin{array}{l}\text { Contribution to } \\
\text { Employment }\end{array}$ \\
\hline $00-01$ & 12.1 & 1.0 & 0.9 & $66 \%$ & 70,000 \\
\hline $01-02$ & 13.4 & 1.6 & 1.5 & $60 \%$ & 106,000 \\
\hline $02-03$ & 16.1 & 2.7 & 2.5 & $68 \%$ & 180,000 \\
\hline $03-04$ & 21.5 & 3.9 & 3.6 & $44 \%$ & 253,500 \\
\hline $04-05$ & 28.2 & 5.7 & 5.1 & $46 \%$ & 348,000 \\
\hline
\end{tabular}

Sounce: NASSCOM, 2005 
Table 2. Comparing alternate destinations for offshore sourcing of BPO

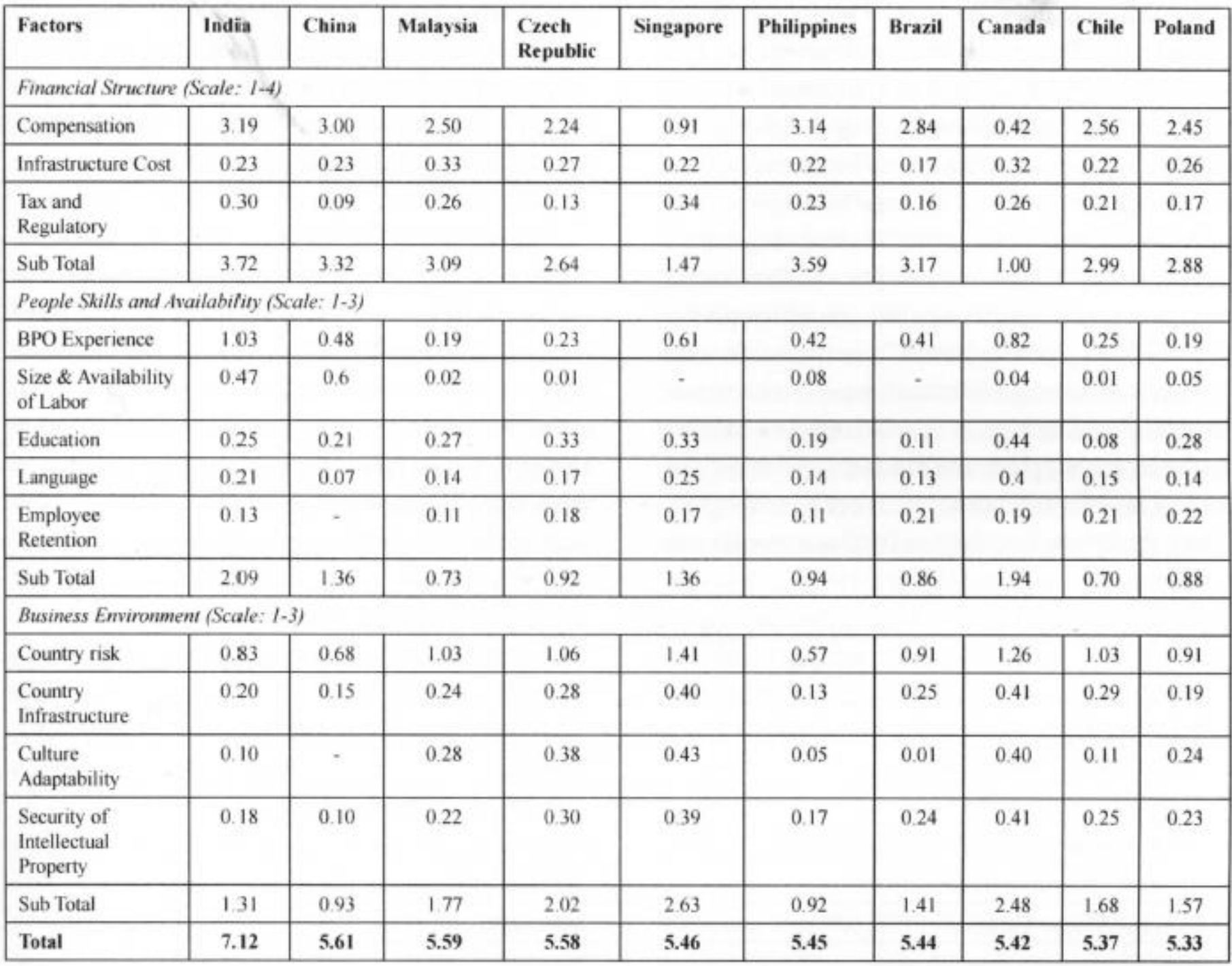

What is the nature of work in the BPO industry? Customer care and support services (call centers) are the largest "service" lines, accounting for close to $38 \%$ of the BPO sector's employee base and a third of its revenues (NASSCOM, 2005). For example, Delta Airlines outsources parts of its worldwide reservation services to an Indian third-party vendor called Wipro Spectramind. Wipro now manages Delta’s reservations from its Mumbai call center and saves Delta \$26 million per year (Kalakota\& Robinson 2004). Similarly, Amazon.com outsources some of its customer service operations to Daksh (now owned by IBM) in order to respond quicker to e-mail from customers. Today, several hundred Daksh employees work exclusively for Amazon.com and they reply to $95 \%$ of e-mail received within 24 hours and $100 \%$ within 48 hours. This saves money for Amazon.com too since a full-time customer service representative would cost Amazon.com $\$ 2000$ per month in the U.S., while an equivalent representative costs $\$ 150-S 200$ per month in India (Kalakota et al., 2004).

Note that these customer service center jobs are similar to the customer service jobs elsewhere that have been studied extensively (see Batt, Doellgast, \& Kwon, 2006 for detailed comparative evidence). As such, work organization in this industry follows closely the "tayloristic" model (see Remesh (2004) for a description of the average customer service center operation). Although the work is done in a "high-tech" environment with the latest in telecommunications and videoconferencing technology, it is relatively low skilled work. However, since the market is primarily in the U.S. and the UK, a knowledge of good English is key. And therefore, Indian BPO companies are forced to hire post-graduates and graduates from a variety of disciplines (a graduate from a good university guarantees, generally 
speaking, some English language capability). Thus, these are highly educated workers, perhaps over-qualified for the jobs that they do, that are in demand in the BPO industry.

Other high growth segments in the industry include human resource outsourcing and legal and medical transcription services. Big human resource consulting firms such as Exult and Hewitt have realized that much of their lower skilled payroll and benefits functions could be relocated to India. Legal transcription services constitute the conversion of interviews between clients and lawyers into documents to be presented in court.

Table 3. Notable captive and third party outsourcers in India

\begin{tabular}{|c|c|}
\hline Captive & Third party \\
\hline Banking and Financial Sector & WNS Global Services \\
\hline Fidelity, HSBC, Deutsche Bank & WIPRO BPO \\
\hline American Express, Goldman Sachs & HCL Technologies BPO Services L.td. \\
\hline Bank of America, Standard Chartered & IBM - Daksh \\
\hline JP Morgan, ABN Amro, Goldman Sachs & ICICI OneSource Ltd. \\
\hline Prudential, Morgan Stanley, & EXL-Services \\
\hline Lehman Brothers & Mphasis BPO Services \\
\hline Professional Services & Intelenet Global \\
\hline Mckinsey \& Co, Accenture, Bain & GTL L.td. \\
\hline Deloitte, Ernst \& Young, Reuters & Progeon \\
\hline Technology and Telecom & 24-7 Customer \\
\hline HP, IBM, EDS, DELL & Datamatics Technologies \\
\hline Samsung, HONEYWELL & Hinduja TMT \\
\hline Automotive \& heavy Machinery & Trans Works Information Services \\
\hline General Motors, Ford & Tracmail Group \\
\hline Daimler-Chrysler, Hyundai & Convergys India Services Private Ltd. \\
\hline Pharmaceuticals & Zenta India Private Ltd. \\
\hline Eli Lilly, Vision Health Source & vCustomer \\
\hline Pfizer, Astra-Zeneca & Sutherland Technologies \\
\hline Others & $7 x$ \\
\hline \multicolumn{2}{|l|}{$\mathrm{AOL}$} \\
\hline TESCO & \\
\hline
\end{tabular}

Source: NASSCOM, 2005

There has also been a long established tradition of the outsourcing of medical transcription. These are the typical, mundane, fairly low skill, limited complexity jobs that form a majority of the work in the BPO industry.

However, the composition of work being undertaken in the BPO segment is in transition and there is a shift toward "high-end" outsourcing involving more advanced skills. There has been growth in higher-level technical support, account management, customer data analysis, and hosting of technology that allows for interaction with the customer. Further, new high-end BPO services are emerging and are growing rapidly, though from a small base. Over the last two years, a number of highly skilled jobs in the West have been outsourced to India. These jobs are mostly concentrated in the financial, research and pharmaceutical industries, leading to the terms financial process outsourcing (FPO), research process outsourcing (RPO), and knowledge process outsourcing (KPO). 
In the FPO area, equity research, actuarial analytics, data modeling, risk assessment, management of foreign commodity accounts, and the processing of home loans and mortgage services are being outsourced by the big U.S. and European companies. For example, Smart Analyst Inc. and OfficeTiger employ financial analysts in India who can scrutinize personal credit histories, access corporate public financial disclosures, and troll oceans of economic statistics by mining databases over the Web ("New Global Shift" 2003). In the RPO arena, the kind of work being outsourced includes developing data search tools for medical research, medical research and services (clinical trials), drug development research, and engineering design. The U.S. Dept of Labor estimates that over 36,000 jobs in life sciences will move to India. A number of research and development centers have already been established (e.g., Siemens, Snecma Aerospace, Sun Microsystems, Samsung, Phillips, Delphi, Daimler, and Bosch). Finally, in the catchall KPO arena, we find the outsourcing of a variety of activities including publishing services, remote education (such as providing math tuition to U.S. school children in the Southwest), animation and simulation, and general research and development. Many of these jobs require advanced degrees. Table 4 shows the spectrum of BPO work being undertaken in India.

\section{THE TURNOVER PROBLEM}

It is clear that the BPO industry will not be able to maintain its current growth rate without solving its biggest human resources problem (i.e., employee turnover, a problem that has become apparent since 2004). The dimensions of the turnover problem are large

\section{Table 4. The spectrum of work done by Indian BPO Firms}

\begin{tabular}{|l|l|l|l|l|l|}
\hline $\begin{array}{l}\text { Customer } \\
\text { Interaction } \\
\text { Services }\end{array}$ & Data Processing & $\begin{array}{l}\text { Skilled Support } \\
\text { Services }\end{array}$ & $\begin{array}{l}\text { Knowledge Process } \\
\text { Outsourcing }\end{array}$ & $\begin{array}{l}\text { Financial Process } \\
\text { Outsourcing }\end{array}$ & $\begin{array}{l}\text { Research Process } \\
\text { Outsourcing }\end{array}$ \\
\hline $\begin{array}{l}\text {-Product } \\
\text { Care }\end{array}$ & -HR administration & $\begin{array}{l}\text {-Publishing } \\
\text { services }\end{array}$ & $\begin{array}{l}\text {-Knowledge } \\
\text { management }\end{array}$ & $\begin{array}{l}\text {-Equity } \\
\text { research }\end{array}$ & $\begin{array}{l}\text {-Life sciences } \\
\text { research }\end{array}$ \\
\hline $\begin{array}{l}\text {-Billing } \\
\text { services }\end{array}$ & $\begin{array}{l}\text {-Insurance } \\
\text { claims }\end{array}$ & $\begin{array}{l}\text {-Graphic } \\
\text { design }\end{array}$ & $\begin{array}{l}\text {-Business } \\
\text { Intelligence }\end{array}$ & $\begin{array}{l}\text {-Data } \\
\text { analysis }\end{array}$ & -Clinical trials \\
\hline $\begin{array}{l}\text {-Tech } \\
\text { support }\end{array}$ & $\begin{array}{l}\text {-Medical } \\
\text { transcription }\end{array}$ & -Accounting & $\begin{array}{l}\text {-Internet based } \\
\text { tutoring }\end{array}$ & $\begin{array}{l}\text {-Market } \\
\text { research }\end{array}$ & $\begin{array}{l}\text {-Engineering } \\
\text { design }\end{array}$ \\
\hline -Marketing & $\begin{array}{l}\text {-Legal } \\
\text { transcription }\end{array}$ & $\begin{array}{l}\text {-Tax } \\
\text { databases }\end{array}$ & $\begin{array}{l}\text {-Customer } \\
\text { data mining }\end{array}$ & $\begin{array}{l}\text {-Semiconductor } \\
\text { design }\end{array}$ \\
\hline Low-End - & & &
\end{tabular}

standards. A wide variety of turnover estimates are currently available. Most reports talk about an average of $30-40 \%$ (per year). Commercial and popular reporting tends to focus on the extremes. There have been reports of turnover being as low as $12 \%$ and turnover being as high as $90 \%$. Mccue (1995) cites one large BPO company which claimed that high staff turnover rates had forced it to replace $90 \%$ of the 14,340 employees in it's largely call center-focused BPO business within a year.

A 2004 study of turnover in seven large "third party" call centers showed a wide variation in turnover rates, ranging from as low as $12 \%$ to as high as $62 \%$, with a mean turnover of $30 \%$ (Remesh, 2004). However, turnover in "captive" BPOs is typically much lower than in third party BPOs. In our field research, too, we found turnover rates in five captive firms as being between $15-20 \%$, although some captives reported turnover rates as high as $30 \%$. There is job-based variation in turnover as well. Average turnover in "voicebased processes" is between 45-50\%, while in "non voice" operations it is 15-20\%. Further, "infant mortality" (turnover in the first 45 days of employment after training) in voice based processes is about $20 \%$ (although anecdotal evidence suggests that this figure may vary to a significant extent). 
There are two types of turnover. The first kind is when workers leave the BPO sector altogether. The second is when they leave one BPO operator to go work for another, often lured by promises of higher compensation and superior incentives. Again, we do not have clear data as to which type of turnover presents a bigger problem. HR managers of well-established leading firms in the BPO industry tend to argue that much of their turnover is due to people leaving the industry altogether. However, at the same time, many other HR managers complain that there is a significant amount of job-hopping in this industry. Some argue that the cost of switching employers is really small (all one has to do is to walk down the street to the next BPO and if trained, one would be hired immediately). Several reports suggest that people would be induced to move with relatively small improvements in salary even as little as 500 rupees per month (approximately \$10). Clearly BPO firms see this type of turnover as being significant (despite what HR managers at top firms tell us). Evidence that this kind of turnover is a problem can be seen in the efforts (largely unsuccessful) of large firms in the industry to establish a "no poaching" pact. The key elements in these pacts are that (a) firms will not poach employees and (b) firms will refuse to hire employees from other firms within 3 months of their leaving their last employment. Large BPOs including IBM-Daksh, Dell, and EXL have openly declared the collapse of such pacts suggesting that they are unlikely to work in today's volatile BPO environment (The Economic Times, 2006a).

The problem of turnover and increased costs are interlinked obviously. The shortage of people has by itself resulted in an increase in salaries above the normal range in India (average BPO salaries are increasing at between 10 and $15 \%$ per year). Although salary costs are "taken out of competition" since it affects the whole industry, recruitment and training costs (some of which are firm specific) are also a matter of significant concern. It takes the average high-end call center about 14-16 weeks of training before an employee is ready to work. Moreover, the current average recruitment conversion rate (the number of people who are actually hired as a percentage of the total number interviewed) is really low (4\%) in the big metros where these BPOs are located. Therefore, turnover is a critical problem for BPO firms.

\section{CAUSES OF TURNOVER}

Interviews with human resource managers highlight a variety of reasons why employees leave their jobs. Since the BPO industry is less than 10 years old, and has grown dramatically in the last five, high turnover has only recently become apparent, and there has been relatively little analysis as to which causes are the most important. We also do not know whether turnover as a result of people leaving the industry altogether is higher or lower than people moving from one company to another within the industry (anecdotal evidence suggests that the latter is the more critical problem, but we need more analysis to make sure). Evidence from the HR departments of various BPO firms suggest the following reasons for high turnover.

\section{Job Related Reasons}

There are several job related reasons, but this category is by far the most important cause of turnover. One important issue here is dissatisfaction with the immediate supervisor (the "lousy boss syndrome"). The BPO segment is less than 10 years old years old and most of the employees are between the ages of 19 to 27. Given the high turnover, people with only 6 months of BPO experience are often promoted to the position of supervisor to manage teams of 10 to 15 people. However, they receive insufficient training due to rapid growth and turnover, and lack significant managerial expertise, thus rendering them ineffective at supervision. Human resource professionals label this the "managerial bandwidth" problem and liken it to attempts at creating a "10 year old scotch in 2 years."

A second job-related problem is inherent in the nature of the work itself. Unlike other high-tech work, BPO jobs are not intrinsically

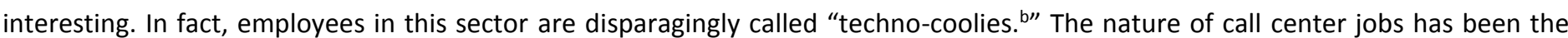
subject of widespread research since it is the primary reason for turnover in this sector all over the world (Batt et al., 2006, Deery \& 
Kinnie 2004). It is widely acknowledged that call center jobs are highly repetitive and tayloristic in nature, with tightly regulated lunch and restroom breaks, stringent call targets, and extensive monitoring. Indian call centers are apparently no different, as Remesh (2004) suggests from his extensive research on call center jobs in India. These aspects, in combination with working the night shift in order to service the U.S. market by day, have resulted in an outgrowth of what the industry calls BOSS (burnout stress syndrome). There are numerous reports of call center workers using counseling and psychological services (Pandey \& Singh, 2005). Besides, dealing with customers can be tedious in itself. And in this way, employees soon begin to see call center work stripped of its glamour and leave within a couple of years.

Third, avenues for career development in many BPO firms are limited. This is supported by our research and other existing evidence. Batt et al.'s (2005) survey of 60 call centers revealed that while $15 \%$ of call center workers were promoted to higher positions within the call center setup, only $1 \%$ was promoted to upper management levels beyond the call center section of the organization. Our research provides more nuanced insights. We find that captive call centers are able to provide promotions to higher levels than "third party" call centers. The market stability that captive call centers enjoy permits them to do so through an envisionment of longterm career paths for their BPO employees.

\section{Demographic Profile of Workers}

A second category of causes relate to the segment of the labor market that BPO work attracts. The workforce is young (primarily aged between 18 and 25), and tend to view BPO jobs as transitory (i.e., their goal is to earn good money for a couple of years in the BPO sector before moving on in life) (the average BPO and call center salary of Rs. 10,000 per month represents about 2.5 times what a graduate could earn in any other occupation) (Knowledge@Wharton, 2004a). Remesh (2004) presents a more nuanced picture by studying a cross-section of workers in a large third party BPO. His survey of 277 workers suggests that $75 \%$ of BPO workers are graduates of convent schools (private schools that are more expensive but noted for their superior English-medium education, typically run by catholic or Protestant churches). Ninety-four percent of their fathers and $63 \%$ of their mothers are graduates, many of whom work for the government. And they are predominantly female. This reflects a slice of the Indian middle class that has no incentive to settle for a call center job. Many aspire to high-level professional or government jobs, or further education at the graduate level, while others leave to get married and start a family.

\section{Psycho-Social Factors}

A third category of causes are psychological factors that are in part related to the demographic profile previously noted. Working the night shift leads to chronic fatigue and insomnia, and is also linked with behavioral changes such as smoking and a poor diet among young graduates. Some workers gain weight because of the sedentary lifestyle the job promotes, involving working on a computer at night and sleeping during the day with little exercise in between. Contact with family and friends is also restricted. These young people work at night, go back to their families during the day, but find no one at home as they have all gone to work. Although there is a long tradition of night shift work in blue collar occupations all over the world, young upper middle class Indian graduates are less able to deal with the absence of a "social life" in the evenings. Further, Pradhan and Abraham (2005) argue that using a different name and adopting a different persona during work hours can cause a questioning of one's identity and can lead to what they term the "multiple personality disorder." (Several client firms from the U.S. require Indian call center workers to adopt American names and American accents). For example, Anjali becomes Angie during the night and talks with an American accent to American customers, leading to cultural self-alienation and a sense of dissonance. All these are sacrifices that a young graduate is either not willing to make or has difficulty dealing with. 
To compound matters, some middle-class parents disapprove of BPO jobs, leading to an increase in stress for these young graduates. Parents for example, fear that the BPO lifestyle is a corrupting influence with too much emphasis on fun and western forms of life. Pradhan et al. (2005) suggest that "the new working habits and patterns of living (i.e., working late into the night, the pub culture, the consumerism) are incomplete contrast to ways of living together, value systems, traditions, and beliefs still nurtured by the middle class." Other parents disapprove because they feel that their children are lured by easy money and will forgo the chance to pursue higher education. Yet others worry about the reputation of their daughters. ${ }^{c}$ Consequently, young people face a variety of different stressors that lead to their decisions to leave the company.

The relative importance of the various factors noted above is still unknown. Turnover as a function of having a lousy boss tends to involve people leaving for other jobs within the industry. Those experiencing the stress syndrome and multiple personality disorder tend to leave the industry completely, and in many cases, those wishing to pursue graduate education and marriage also tend to leave the industry completely. Firms are in the process of putting in place a range of policies designed to combat turnover, which we discuss in the next section.

\section{HUMAN RESOURCE POLICIES TO REDUCE TURNOVER}

Indian BPOs are experimenting with a range of strategies to reduce employee turnover. Our goal in this section is to describe the various approaches. In the discussion section, we will take a more analytical perspective regarding these strategies, using the prior literature to gain a perspective regarding the relative efficacy of these approaches. At this stage, we classify the responses of firms into two broad categories (i.e., "traditional" approaches and "new" approaches).

Our category of "traditional" includes a variety of strategies by firms that correspond broadly to the existing academic literature on employee turnover. In the field of human resource management and organizational psychology (as represented by journals such as the Academy of Management Journal, the Journal of Applied Psychology, the Journal of Management, etc.), the problem of turnover has been studied almost incessantly for almost 50 years, beginning with the work of March and Simon (1958), and there have been several meta-analyses that have reviewed past studies (see Griffeth, Horn and Gaertner, 1998). Broadly this voluminous and cacophonic literature suggests (as we gleaned from a reading of several "meta-analytic" studies) that the most important predictions of turnover are variables such as job satisfaction (including satisfaction with various dimensions or facets of the job), organizational commitment (which is predicted by both job satisfaction and a number of other variables), and the perceived ease of finding alternative employment. Therefore, any action by firms to promote job satisfaction (or satisfaction with various aspects of one's employment), we categorize as "traditional" approaches. As the discussion below shows, this includes a variety of different initiatives.

Our category of new approaches below is much smaller, yet more interesting, as they do not fit easily into the prior turnover literature. Rather, these approaches appear to conform more to the notion that it is not the job that matters as much, but the culture of the organization and a variety of "non-job" aspects that are important in employee retention. There is, for example, an emerging literature in management that focuses on "job embeddedness" which highlights an employee's non-job related links to the workplace. Clearly these "new" approaches are consistent with this view, but they go beyond it in many ways, and appear to be tailored to the peculiar characteristics of the BPO workforce in India (i.e., young, upwardly-mobile, highly educated English-speaking middle class people). Next, we describe the strategies.

\section{TRADITIONAL STRATEGIES}

\section{Increasing Career Opportunities}

In response to perceptions that BPO jobs do not offer career growth, (a widely held perception amongst BPO employees) 
employers are going to great lengths to convince their employees that there are sufficient career growth opportunities. According to a NASSCOM-Hewitt survey, there was a $14 \%$ increase in the number of BPO companies offering a formalized career path to their employees in 2003 alone (NASSCOM 2004). BPOs are actively encouraging employees to move up the ladder and are consciously filling their front-end leadership roles from the talent pool available within the organization. To facilitate this, employees are being crosstrained in multiple domains and are being provided opportunities to work in various lateral departments. Both vertical and lateral movements are important in career development. Thus, BPOs are highlighting that they can offer many career options and functional specializations including project management, IT, systems migration, business process consultancy, training, HR, finance and accounts, quality, business analysis, sales, marketing, proposal development, and the like.

As an example, Intelenet Global Services (one of the larger BPOs) offers career growth options to its agents after two years. The company offers three career paths: vertical (agent/team leader/team manager/operations manager), horizontal (across functions) and progress to parent company (TCS or HDFC). Further, Intelenet has made it clear to its employees that $70 \%$ of its higher level vacancies will be filled from within, ensuring sufficient promotional opportunities for its entry level people. Moreover, they have emphasized that if a vertical movement is not desirable (such as not wanting to be a team leader), a person could move laterally to another function such as HR/ Training and then move vertically upwards from there. Prudential Process Management Services (PPMS), the captive BPO arm of Prudential UK, also offers vertical as well as lateral movements to its employees. The career development streams here are domain specialists, support function specialists and global exchange program (Dev, 2004).

These formal processes are buttressed by individual career counseling and the creation of individual road maps to career advancement. Most BPOs have established in-house counseling teams that offer employees a variety of career advice. Through faceto-face counseling as well as psychometric profiling, these counselors are devising customized action plans for employees based on their aspirations and strengths. In addition, they can assess skill sets and recommend specific career options for workers. Finally, they also offer to work with employees to build skills sets and bridge gaps that would enable them to develop their careers effectively.

For example, at Infowavz International, a relatively newer BPO that operates about three call centers, a career planning sheet is given to all employees at the recruitment stage itself. This outlines the organizational structure and the skill sets required for the various functions at various levels of the enterprise. Apart from this, each individual's competencies, strengths, and areas of improvement are evaluated under a comprehensive 'training needs analysis' program for both current as well as future roles (Dev, 2004). Similarly, Progeon (now called Infosys BPO) has recently started a career planning committee to guide young employees on their future prospects (Mukherjee, 2004). These efforts try to contradict the widely held perception that there are limited career growth opportunities in the business process outsourcing industry, especially by highlighting growth opportunities when people join the industry.

It is too soon to gauge the success of these efforts. Earlier, the "'captive" BPOS were better able to provide career development, largely because they had a stable market for their business. But today, the big third party BPOs such as Infosys BPO and IBM have seen their business grow to an extent to which they can essentially guarantee the same career opportunities as captive BPOs can.

\section{Providing Educational Opportunities}

Recognizing that most young upper middle class Indian graduates have higher educational aspirations (after working at a BPO firm for a couple of years after finishing college), BPO operators are beginning to sponsor executive education for employees. This is quite an extreme strategy since they are providing access to educational opportunities that will almost certainly result in the employees leaving after they complete those opportunities. At best, these efforts will result in prolonging an employees' decision to leave by about $2 / 3$ years. On the other hand, the "war for talent" is so acute that even $2 / 3$ years of stability on the employee front is important 
in this extremely "tight" labor market. Thus, many firms have entered into agreements with premier Indian business schools (e.g. Indian Institutes of Management, Xavier Institute of management) to offer part-time MBA programs for their employees. Employees also have the option of pursuing technical certifications like MCSE and CCNA to gain domain-specific skills in the technology sector (InfotechOnline, 2006). The course content and class timings are tailored as much as possible to the specific students' needs. Mostly, the classes are virtual, offline or held at the educational institutes. But in some cases, they are held over weekends on the BPO firms' campus.

Wipro Spectramind, India's largest BPO company with 9,300 employees, has recently started such an "earn and learn" program. "We have tied- up with educational institutes like Symbiosis for MBA and BITS Pilani for computer courses so that the employees are able to work and study at the same time. We are even ready to reimburse the course fees once the employees enter into an agreement with us for an assured number of years of service," states the VP Talent Engagement and Development at Wipro Spectramind (Shrinate, 2004). This initiative not only "up-skills" workers, but helps Wipro retain their A-level employees, and undoubtedly offers an opportunity to create future industry leaders. Since the idea is to the retain employees, Wipro is not selective about which employees they sponsor (Shrinate, 2004).

Other BPOs, such as TransWorks, Sitel, ICICIOneSource, and BNKelnternational also offer their employees the opportunity to continue studying whilst in full time employment. Some firms conduct internal "entrance tests" to shortlist the promising employees while some others consider past academic performance or performance on the job. At Sitel, any employee can apply for the scholarship program, although preference is given to high performers. At TransWorks, the applicant must have been employed for a minimum of six months and should have performed well on the service level agreements. ICICIOneSource also insists on the six-month rule and encourages only the top performers to apply. There are a variety of post graduate diplomas in subjects such as marketing, finance, and management. There is also diversity among firms as to whether or not they pick up the tab for these educational opportunities. Some firms pay the whole fees, while other provide a subsidy or arrange educational loans. Sitel only picks up half the fees of the student, while TransWorks often reimburses the entire course fee. ICICIOneSource has an upper limit of Rs.25, 000. Further, some BPOs require employees to commit to a minimum period of employment. At Wipro

Spectramind, it is a year, while at ICICIOneSource it is six months (Shrinate, 2004).

This is a germane strategy. It is well known that the typical BPO employee is interested in further professional education. Our interviews with various employees suggest that they value this "perquisite." And although we do not yet have firm data, anecdotal evidence suggests that BPOs who are establishing these programs tend to report lower turnover than those without similar programs.

\section{Leadership Development}

Allied to career development, BPOs are also investing heavily in leadership training. While the motivation here is clearly one of self-interest (i.e., BPOs would like to increase "managerial bandwidth" and thus simultaneously reduce turnover), there is an element of development and longer term career planning here that is of mutual interest to both employer and employee. From the employer's perspective, leadership development is key to establishing a strong middle management cadre, but also increases the loyalty of employees who go through the training. From the employee's perspective, management training complements the career development process and binds the employee more closer to the organization in the longer term.

These training programs are quite intensive and require considerable organizational resources. BPOs are training their employees to motivate their colleagues, instill team spirit, conduct performance appraisals and take on a battery of other responsibilities. At ITC ClientLogic (CLI3L), for example, there is considerable emphasis on training beyond that required for the current job, with a wide span of skills that are covered, from workforce management, coaching and feedback, communication skills and rewarding and recognizing 
staff to understanding of business metrics and Six Sigma (The Economic Times 2005).

\section{Employee Stock Option Plans}

Providing employees with stock options has had a long history of building loyalty and forcing an alignment of employees' longer term goals with the organization's longer term goals. Thus, using stock options as a motivating tool is not new, but in most organizations, this tends to be focused on senior management. Introducing stock options for lower levels of employees, as the BPOs are now doing, is more clearly tied to a retention objective (although $52 \%$ of BPOs provide stock options to their employees, most organizations have a vesting period of between 3-6 years) (NASSCOM, 2005). Among higher end BPOs operating in the financial industry and in bio tech, stock options are common as well.

\section{Job Enrichment}

One of the defining features of a call center job is the repetitive nature of the work. As such, observers of the customer service industry note that these are "lousy" jobs, wherever they are. The intrinsic nature of the work does not seem to vary across countries. However, HR managers in Indian BPOs, facing high levels of turnover in a tight labor market, argue that call center workers can "add more value to a company than just being an outlet for customer frustrations." (InfotechOnline, 2006) Hence, BPOs are outsourcing work like data entry and seasonal work to smaller companies so that their employees get to do high value-added work. For example, E-Edit Solutions, a BPO in e-publishing, outsources basic composition work and XML coding work to multiple vendors (Indiatimes InfoTech, 2006). This way, BPO operators get to work on new technologies. This is not possible in all cases, but the principles are transferable.

These various new initiatives are in addition to traditional strategies of good pay and benefits (which do not vary much across the industry) and good human resource management practices (which varies quite a lot) in the industry. Indian BPO firms are also engaged in a number of other strategies, such as targeting older workers who might be more willing to see this as a long-term career.

\section{NEWER APPROACHES}

\section{Developing a Fun Culture}

A key development is the recent focus of several BPOs in positioning themselves as "fun" places to work in to retain their predominantly young workforce. In general, the approach here is to sponsor fun-filled activities, parties, invest in recreational facilities, construct trendy interiors, encourage employees to watch movies, play games, and relax (when workload is light). The goal of these activities is to create an ambience in which the young educated and middle class workforce will enjoy the work atmosphere and hopefully will not leave. As the Director of Business Developmental Motif a BPO suggests "We understand that salary is only one part of what motivates employees... an agreeable working environment is what really allows us to retain talented individuals." Thus, BPOs are increasingly setting aside a budget for "fun" so as to keep their employees "happy."

At Wipro Spectramind, "everything revolves around fun" according to the VP Talent Engagement and Development (Doke2003). Fun is a core, written-down, defined value and hence, permeates all aspects of life at the organization. Wipro Spectramind's mission statement reads "Together we create a fun-filled work environment, encouraging all to enjoy pushing their individual and original roles." The BPO holds that fun is critical to enhancing mutual trust and building dynamic relationships amongst employees. Further, they believe that fun helps to mitigate stress arising from BPO work and allows employees to maintain high energy levels in their interactions with customers. Thus at Wipro Spectramind, fun is not a reward for performance but a core aspect of the organizational environment. It is even linked to the performance management system whereby employees are rewarded for living up to the value of 
fun in the workplace. As a senior executive warns, "make no mistake, fun is serious business here [as it] helps reinforce the values of the organization" (The Economic Times, 2004).

24/7 Customer has developed a similar company motto: FITO (fun into the organization). By budgeting \$10 million per year for these activities, they ensure an engaging time for all those on their roster. The BPO believes that employees bond through such activities and then go back to work recharged. And strong bonds of friendship certainly help to retain employees in an organization. Fun activities can help foster bonds with customers too. For example, at 24/7, the procurement of an important contract was celebrated with a 30 feet long cake with the customer's logo on it (The Economic Times, 2004).

At HCL BPO and Contech, a balance between fun and work is obtained by pushing the "work hard, party hard" concept. The BPOs recognize that their employees are fascinated with western ways of living and they devise programs that capitalize on this. And as the director of business development at Motif observes, "an agreeable work culture is what allows [BPOs] to retain talented individuals" (O’Driscoll, 2005).

Creating a balance between work and fun in the workplace requires a significant organizational commitment and a variety of activities as the Wipro Spectramind previous example indicates. Thus, there is focus on the physical environment with BPOs making sure that their physical layouts appeal to their trendy workforce. EXE, for example has three state-of-the-art facilities spread over 150,000 square feet at Noida, near Delhi. These facilities have a bright, colorful, and lively design on the shop floors, while exuding elegance and classiness in "common areas" and on the corporate floor. The color schemes are bright and visually appealing, given that BPO work is deskbound, repetitive and sometimes stressful. Bright reds, pinks, and yellows have been used on the shop floor, with a textured finish to counter the glare of the bright walls (Business India Intelligence, 2003). Similarly, there is a focus on recreational facilities, which appeal to the workforce. For example, Infosys' campus houses a state-of-the- art gym, golf course, sauna, 50,000 square feet swimming pool, lake with paddling boats, grocery store, pool tables, ping pong tables, and a dance floor (Infosys, 2001). 24/7 Customer has invested in a complete range of music equipment where their seven in-house rock bands practice during work (The Economic Times, 2004).

Food is also an important aspect of the environment. IBM Daksh offers free breakfast buffets to all their employees (The Times of India, 2004). The Infosys campus contains food courts that serve Chinese, North Indian, South Indian, and Western cuisine (Infosys, 2001). Then there is the focus on wellness. The negative aspects of the call center environment, including night shifts, sedentary work, talking on the phone for hours together, and their associated ailments are now well known. Therefore, specific initiatives are being taken by some BPOs to address nutritional and stress-related concerns that employees might have.

For example, KGISL recently hired a physiotherapist to teach employees exercises for flexing their fingers and toes (Revathy, 2004). While the initiative is small, it is nevertheless an attempt at protecting employees' health and spirit. Other BPOs have initiated various programs like yoga classes, neck and shoulder massages, dietary and nutrition advisory sessions and workshops on managing sleep habits and achieving work-life balance.

To complement the physical attributes of the workplace catering to the young is a focus on an informal atmosphere at work. Many BPOs try to keep the work atmosphere quite informal so that employees loosen up, feel comfortable, and have fun at work. With this in mind, Wipro Spectramind has no dress code. Therefore, torn jeans worn to work are just as acceptable as traditional Indian clothing (Doke, 2003). And there is a focus on "fun-filled activities" at the workplace. Events like treasure hunts, voice impersonations and rangoli competitions are common. At HCL BPO, frequent contests and team dinners are a way of life. At Contech, it is common to walk into the cafeteria and witness a round of musical chairs. Even a one-minute-game-show was organized recently during which employees had 60 seconds to stick as many bindis (Indian adornment) as possible on their colleagues' faces. At Effective Teleservices, each time an agent secures a sale, he or she spins the office's wheel of fortune with the chance of winning a prize. On Halloween 
Monday, the employee with the best costume is awarded a gift. Infowavz International celebrates Rose Day, Friendship Day, Valentines' Day, etc. with great fervor in a way that involves all their employees (O'Driscoll, 2005). Sometimes employees put up cultural shows too. Thus, at these BPOs, at any given point in time, there is something or the other going on, with never a dull moment. And after work, there are parties. Many BPOs sponsor parties for their employees at a nightclub or a discotheque, with unlimited food and drink to ensure a night of partying and fun with friends and colleagues. BPO workers enjoy this immensely as it legitimizes partying by making it 'official' and therefore allows them to elude late night curfews imposed by strict parents. And there are trips. BPOs are organizing regular outings too, as an opportunity for their employees to bond with one another and with their company outside of work. There are day trips to malls, weekend trips to resorts, and so forth. And finally, various Indian festivals are celebrated on company time and at company expense.

To coordinate all these activities, BPOs have hired a new cadre of employees called "fun officers." For example, Progeon (now called Infosys BPO) has hired a "chief fun officer" (CFO) who articulates new "fun" strategies (Mukherjee, 2004). In other BPOs, fun teams are in charge of spur of the moment activities including pizza parties, outings, and picnics. At Wipro Spectramind, each supervisor is rated for his or her efforts to encourage team members to organize and participate in events and group activities (Shahane, 2005). Clearly there is an organized effort to promote fun as a central element of one's employment at a BPO in India.

\section{Developing Family Friendly Practices}

A second key element that is new is the effort to integrate the employee's family into the enterprise in some way. The underlying notion here is that if the family is engaged, then there is greater likelihood of employee retention, as the employee's family is also in some way "embedded" in the organization. Infosys BPO and TransWorks have instituted periodic family days for their employees to show off their workplaces to their parents, siblings, partners, and kids. It is also an educational experience for family members as they learn about the various facets of life in the BPO industry and are introduced to team leaders. In the words of a VP of Human Capital at TransWorks "The objective is to familiarize families with the nature of the industry and the work done, so that they feel proud of their children" (Ganesh, 2006).

The family is also integrated into the reward systems of the enterprise. "When an employee has performed well, we call up the parents or the family members concerned and tell them about the employee's achievement," claims a lead executive of Accenture's India Delivery Centre (Ganesh, 2006). On similar lines, when an employee recognition ceremony took place earlier this year at Wipro's headquarters in Bangalore, all awardees along with their spouses from locations across India, were flown down exclusively for the ceremony. And then there is this notion of "sharing the gains." When Cognizant reached its \$ 1 billion revenue milestone, it celebrated by doling out the latest $5^{\text {th }}$ generation iPods to 15,000 employees who had served the organization for over a year (Chatterjee $\&$ Ramnarayan 2006).

Integrating the family at the time of hiring is also common. In their own way, BPOs are addressing parental queries about their ward's job profile, career opportunities, and the workplace environment. Accenture's BPO arm has even re-engineered its hiring process to involve employees' families right from the interview stage to the post-recruitment phase. During the advanced stages of an interview, the company asks the prospective candidate to bring his or her family or spouse along. "We want them to have a personal feel about our workplace and deal with their apprehensions, if any, then and there," says the VP HR, Convergys India, who invites parents of new recruits to the firm (CiteHR, 2004).

And specifically geared to retention, many BPOs offer fully paid family vacations for longer service. Wipro Spectramind gives out two-three day holiday packages to an employee's entire family for a destination within India in appreciation of the employee's long stint in the organization (Chatterjee et al., 2006). 
Finally, there is the notion of work-family balance, a response to the problems expressed by young people. For exam pie, at Wipro Spectramind, there are times when an employee needs temporary leave from work when his or her partner has been posted abroad. Such requests are accommodated as far as possible. When a husband and wife pair works for Wipro, the company tries to ensure that both of them are always placed at the same location. Global Logic BPO bears the travel expenses of their employee's spouse and dependant children if the employee is required to travel abroad for more than three months on B1/L1/H1 visas (Shahane \& Savitha, 2007).

Perhaps the most radical effort at retention is the complete embedding of the family at the workplace: BPOs are encouraging entire families to work together in the company. One pioneering New Delhi based call center, Vertex, with over 900 employees popularized this concept. "They are several couples employed here, a mother and son duo, and an instance of 3 brothers but this is just the beginning," according to the CEO of Vertex India. The idea was explored when some employees who were leaving said they were doing so because they hardly spent time with their families as a result of working night shifts while their spouses were asleep. But now, families can travel together to work, spend time at work and also while commuting back home. Vertex is hoping that the emotional bond to the company will be stronger now that family ties are involved (InfotechOnline 2004b). Ness Technologies, too, always makes a job offer first to an employable spouse before moving to the general pool of applicants. "We also retrain the person if necessary," claims the VP HR at Ness Technologies (Shahane et al., 2007).

In sum, the "new" strategies category appear to focus on the one hand on non-work related aspects of the organization that serve to make their BPO an attractive environment to work, while simultaneously attempting to increase the commitment of employees family's to the organization in order to increase employee retention. These strategies have not received much attention in the voluminous research on turnover.

\section{DISCUSSION}

As noted, it is too early to comprehensively evaluate the effectiveness of these ongoing retention strategies. From a more analytical perspective, it is clear that the "new" strategies are qualitatively different from the traditional variables highlighted in prior turnover research. Removing the causes of job dissatisfaction is important, as demonstrated by prior turnover research. But the interesting aspect of the "fun" and "family integration" strategies is that they tend NOT to focus on the most fundamental issue (i.e., the job ${ }^{d}$ ). Thus, the new strategies give great emphasis to the creation of an organizational culture that provides some avenues for "fun" and "family integration" without addressing fundamental issues with the job itself. This approach appears to turn decades of turnover research on its head.

On the other hand, it is possible that decades of turnover research has not focused appropriately on the importance of such approaches. However, there is a new strand of research on turnover that seems consistent with the new approaches described in this chapter (Mitchell, Holtom, Lee, Sablynski, \& Erez, 2001). They focus on the concept of "embeddedness," which refers to three interrelated notions: the extent to which people have links to other activities at work, the extent to which their jobs and communities are similar to or fit with other activities in their life spaces, and the ease with which these links can be broken. As Mitchell et al. (2001, p. 1104) note, "we can describe embeddedness as like a net or web in which an employee has become stuck." The higher the number of links between the person and the web, the more the person is "bound" to the organization. Thus, it is possible that an employee can become enmeshed or embedded in many different ways. For example, an employee will consider how well he or she fits in the work community and the organization, and therefore issues like amenities, outdoor activities, social and entertainment activities all play a role in this notion of fit (Mitchell et al., 2001) that leads to organizational attachment.

This notion of embeddedness, is quite consistent with the concept of organizational culture (in fact, most HR managers used this 
term), although culture has NOT been an important variable in turnover research (thus far). Clearly Indian BPOs are 'engineering' a particular type of culture that increases the embeddedness of the employee in the work environment. Whether the focus on increasing employees' embeddedness through the creation of a particular type of culture apparently will have a positive effect on retention remains an open question; more systematic research is necessary to firmly establish its effectiveness.

We do however, have some preliminary anecdotal evidence regarding the effect of both classes of strategies. First, on average, we find that turnover levels at captive firms tend to be lower than those at third party BPOs (in our sample of firms, turnover ranged from 15-20\%), consistent with our expectations that captive firms have a more stable environment. Second, we know that at Sitel, the attrition rate is down to $30 \%$ from $37 \%$ in just 8 months as a result of the part-time educational opportunities (Shr inate, 2004). Also, "new" strategies at 24/7 Customer has reduced "infant mortality turnover" to less than 2\% (Menon, Sinha, \& Urs, 2004). Finally, in a recent Dataquest-IDC survey measuring the satisfaction level of BPO workers, IBM (previously Daksh) emerged on top as a result of high satisfaction scores on a variety of human resource dimensions, including work culture and image. This is despite their low rank on "employee satisfaction with wages." (InfotechOnline, 2004a). As a result of Motifs fun at work strategies $97 \%$ of Motif employees said in the same Dataquest- IDC survey that they "look forward to coming to work in the morning."

By creating a young employee-friendly work environment, KG1SL reports that it has managed to contain their attrition rate at between 5-8\% (Revathy, 2004). Similarly creative human resource management initiatives geared towards fun at Effective Teleservices have helped the company maintain an impressive 5.2\% attrition rate (O’Driscoll, 2005). Thus, the preliminary evidence suggests that both types of strategies appear to be delivering results.

However, there is also some recent evidence of a dissatisfaction and disillusionment with these strategies as well. The chief personnel manager of 24/7 notes that "some BPOs have gone overboard with the fun theme" (The Economic Times 2006b). With the "fun" approach, the seriousness related to doing business had gone, particularly as BPOs moved up the value chain and started doing more value added work. At $24 / 7$ the company has newly introduced a formal corporate dress code, and is attempting to draw a line between work and fun (The Economic Times, 2006b). And as the chief delivery officer of the company notes, they are trying to now convey to employees that working for a BPO is not fun, but a serious career (Borthakur, 2006).The Chief Executive of Progeon, for example, notes that the concept of "having fun at work" was necessary in order to attract young people to work in the industry, but now employees have realized that working in the outsourcing industry involves serious work. Similarly, a senior vice president at another BPO argues that "during the initial phase of the BPO industry, branding BPO work as "fun" was a way to attract and retain these young kids to work" (Borthakur, 2006). But now, with maturation, it is necessary to re-brand the business. Bakshi (2005) suggests that "although the fun factor has not been thrown out of the window, it has taken the backseat" and that career planning and development are replacing the "fun" factor as the key to retaining employees. Recruitment advertisements for BPOs do not emphasize the fun factor as much anymore, while highlighting the career growth possibilities in the industry. The VP HR of Tracmail argues "it is high time the industry realizes that showcasing the BPO space as a fun extension of college life is grossly incorrect" (Offshoring Times, 2005). The president of NASSCOM (the industry association) notes that companies are now shifting to growth prospects as a prime motivator rather than concentrating on fun initiatives to retain talent (Bakshi, 2005).

Although the evidence above is anecdotal, it is clear that some BPOs highlight the importance of the culture of fun, while others question its effectiveness. Clearly, there is some ambiguity here. What explains these differing perceptions on the importance of the "culture" strategies? We offer two tentative and inter-related explanations here. First, we argue that the given the recent evolution (the last 8 years) and the rapid growth and development of the industry (average annual growth rates exceed 50\% - see Table 1) under tight labor market conditions, firms were following a "scattergun" approach, experimenting with a variety of strategies to solve the turnover problem. Many HR managers told us that all they seem to do is "recruit, recruit, and recruit." Thus organizations have just 
not had the time during this period of breakneck growth to establish coherent human resource policies. As some of the comments above seem to suggest, the last year has seen some maturation in the industry, where some of these culture strategies are being reevaluated.

Second, we argue that it is probable that strategy of creating a "culture of embeddedness" is too narrow in its focus. Kunda (1992) suggests that an organizational culture is "engineered" (i.e., researched, designed, developed, and maintained) to attain certain strategic goals. The culture defines the social characteristics of the company and acts as a guideline for company action. Overtime, the grasp of this culture runs even deeper to control the "mindsets" and "gut reactions" of the employees by creating in them a strong commitment to the company and identification with company goals (Schein, 1985). There is considerable evidence that companies with strong corporate cultures are successful (Deal \& Kennedy 1982). Organizations with a strong culture create clear and coherent values (Chatman \& Cha, 2002; Saffold, 1988), increase organizational performance via a better understanding of organizational objectives and increase inter-personal ties (Deal et al., 1982; Pottruck \& Pearce, 2001; Tushman \& O'Reilly, 1997). And there is evidence from studies of several organizations (e.g., Southwest airlines) that companies with strong cultures attain a variety of strategic advantages (Friedberg \& Friedberg, 1996; O’Reilly \& Pfeffer, 2000a). Further, strong cultures create organizational stability (Denison \& Mishra, 1995), which appears to be the need of the hour for Indian BPOs.

The debate about the usefulness of these "fun culture" strategies in Indian BPOs is, in our view, a reflection of the narrow focus of these strategies. Indian BPO strategies on culture appear to concentrate on the creation of an environment that promotes retention, and less on the creation of a culture to accomplish broad organizational goals. Their HR initiatives, for example, focus on social engineering in the BPO workplace to create a fun, nurturing environment. Through the provision of various social activities, these initiatives establish communal ties among employees to the extent that the workplace becomes the focal point of social interaction. This is further buttressed by various policies that link employees' families to their workplaces, further binding employees to the organization. This is a human resource initiative, not an effort to create a particular shared culture by officially propagating "values" and having employees interpret them (Hochschild, 1997).

We think that what is really going on is that BPOs have failed to integrate the two categories of strategies effectively and have been as yet unsuccessful in creating a strong organizational culture that promotes not just retention but overall organizational performance. For these efforts to be successful, a more integrated corporate culture approach such as that suggested by Kunda and others may well be necessary. What appears to be required is an integrated strategy that develops a strong organizational culture, one that in the long term aligns individual and organizational goals in a more serious way. We leave it to future research to investigate our tentative hypotheses further.

\section{CONCLUSION}

In this chapter, we briefly described the problem of high turnover in the high-tech BPO sector in India. We highlighted the various approaches to solving the turnover problem (which are currently ongoing). Although we do not have evidence yet of the effectiveness of these strategies, based on anecdotal evidence and interviews with industry personnel, we sense some ambiguity regarding the effectiveness of these strategies. We argue that this ambiguity is a function of (a) the recent and rapid growth of the industry and the fact that firms are experimenting with a variety of strategies to limit turnover, and (b) the inability of firms to develop an integrated organizational culture that perm its a focus on both longer term organizational performance, as well as retention.

The chapter is focused on highly educated workers, many of whom are working in low skilled jobs in the high tech environment of the outsourcing industry in India. There is a contradiction here. These employees are way too overqualified for the low skill jobs that they do. It is not surprising that turnover is high, given the nature of the work itself. Yet the employees are critical to the growth 
of India's BPO industry. Perhaps the answer in the longer term is to recruit employees with lower qualifications who will be more likely to see these jobs as providing long-term careers. However, this would require the Indian education system to graduate more English speakers. Alternatively, maturity and consolidation in the industry will provide a more stable basis for more effective human resource policies to contain attrition. Until then, Indian BPO employees are "having fun."

\section{REFERENCES}

Bakshi, M. (2005, March 28). Heard you, loud and clear. The Hindu Business Line. Retrieved March 9, 2007, from http://www.thehindubusinessline. com/ew/2005/03/28/stories/2005032800200300. htm

Batt, R., Doellgast, V., \& Kwon, H. (2006). Service management and employment systems in U.S. and Indian call centers. In L. Brainard \& S. M. Collins ((Ed.), Offshoring white-collar work: The issues and implications. The Brookings Trade Forum,2005.(pp.335-361). Washington, DC: The Brookings Institution.

Batt, R., Doellgast, V., Kwon, H., Nopany, M., Nopany, P., \& da Costa, A. (2005). The Indian call centre industry: National benchmarking report strategy, HR practices, \& performance (CAHRS Working Paper \#05-07). Ithaca, NY: Cornell University, School of Industrial and Labor Relations, Center for Advanced Human Resource Studies, http://digitalcommons.ilr.cornell.edu/ cahrswp/7

Borthakur, M. (2006, Nov. 9). BPO: Only business. The Times of India. Retrieved March 9, 2007, from http://timesofindia.indiatimes.com/ articleshow/374855.cms

BusinessWeek Online. (2003). The new global shift. Retrieved December 20, 2006, from http://www.businessweek.com/magazine/con-tent/03 05/b3818001.htm

Chatman, J. A., \& Cha, S. A. (2002). Leading though organizational culture. In S. Chowdhury (Ed.), Next generation business series: Leadership. Financial Times. Prentice Hall Publishers.

Chatterjee, M. B., \& Ramnarayan, A. (2006, April 10). For you and your family. The Hindu Business Line. Retrieved March 10, 2007, from http://www.hinduonnet.com/ the- hindu/thscr ip/pr int.pl?fi le=2006041000010100. htm\&date=2006/04/10/\&prd=ew\&

CiteHR. (2004). BPOs encourage parents day out. Retrieved March 10,2007, from http://www.dtehr. com/bpo-india=bpo-indusrtyvf7396.html

D'Cruz, P., \& Noronha, E. (2006, May 27). Organising call centre agents: Emerging issues. Economic and Political Weekly. Retrieved February 27, 2007, from http://www.epw.org.in

D’Cruz, P., \& Noronha, E. (2006). Being professional: Organizational control in Indian call centers. Social Sciences Computer Review, $24\{3), 342-361$.

Deal, T., \& Kennedy, A. (1982). Corporate cultures. Reading, MA: Addison-Wesley.

Deery, S., \& Kinnie, N. (2004). Call centres and human resource management. Hampshire: Palgrave Macmillan.

Denison, D. R., \& Mishra, A. K. (1995). Toward a theory of organizational culture and effectiveness. Organization Science, 6, $204-223$.

Dev, S. (2004, Jan. 26). ITES Players offer longterm careers. IT People, S(18), 1-2.

Doke, D. D. (2003, April 29). What makes Indian call centers tick. Personnel Today, 6-8.

Dossani, R., \& Kenney, M. (2003). Went for cost, stayed for quality? Moving the back office to India. Berkeley Roundtable on the International Economy. Berkeley, CA: University of California.

DTA Consultants. (2004). The Indian IT and IT-enabled services Industry. Retrieved January 20,2007, from http://www.dtainternational.com/ ITES in Indiall.pdf

Economist Intelligence Un it. (2003). Finding staff and keeping them. Business India Intelligence, 70(1), 5-8. 
Friedberg, K., \& Friedberg, J. (1996). Nuts! Southwest Airlines ' crazy recipe for business and personal success. Austin, TX: Bard Press.

Ganesh, V. (2006, December 1). Want to retain staff? Keep it in the family, say BPOs. Hindustan Times. Retrieved from http://www.hindustan- times.in/news/ 1811857532,00020021.htm

Griffeth, R. W., Horn, P. W., \& Gaertner, S. (1998). A meta-analysis of antecedents and correlates of employee turnover: Update, moderate testes, and research implications for the millennium. Journal of Management, 26, 463-488.

Hochschild, A. R. (1997). The time bind: When work becomes home and home becomes work. New York: Metropolitan Books.

Indiatimeslnfotech. (2006). BPOs outsourcing work to smaller cos. Retrieved January 5, 2007, from http://infotech.indiatimes.com/BPOITES/Outsourcing/BPOs outsourcing work to smaller cos_/articleshow/2011023.cms

Infosys. (2001). Management of human assets at Infosys. Retrieved March 10, 2007, from http:// www.infosys.com/about/cases/INFOSYS6\%20case\%20w ithchanges.pdf

InfotechOnline. (2004a). BPO workers more satisfied now. Retrieved November 10, 2006, from http://infotech.indiatimes.com/articleshow/msid-919912.cms

InfotechOnline. (2004b). Invited! Your family for the BPO job. Retrieved January 5, 2007, from http://infotech.indiatimes.com/articleshow/msod-94075l.cms

InfotechOnline. (2006). BPOs take care of your career too. Retrieved September 5, 2006, from http://infotech.indiatimes.com/articleshow/msid-1456697.cms

Kalakota, R., \& Robinson, M. (2004). Offshore outsourcing: Business models, ROI, and best practices. Alpharetta, GA: Mivar Press.

Knowledge@Wharton. (2004a). A view from the developing world. Retrieved January 25, 2007, from http://knowledge. wharton.upenn.edu/article.cfm?articleid=860

Knowledge@Wharton. (2004b) Why corporations pursue BPO. Retrieved February 25, 2007, from http://knowledge. wharton.upenn.edu/article.cfm?articleid=860

Kunda, G. (1992). Engineering culture: Control and commitment in a high-tech corporation. Philadelphia: Temple U.P.

March, J. G., \& Simon, H. A. (1958). Organizations. New York: Wiley.

McCue, A. (2005, January 21). High staff turnover hits Indian offshore firms. Offshoring Special Report. Retrieved December 15, 2006, from http://www.silicon.com/research/specialreports/offshoring/0,3800003026,39127243,00.htm

Menon, S., Sinha, S., \& Urs, A. (2004, August 1). Tug of talent. The Economic Times, p. 7. Kolkata, India: The Times Group.

Mitchell, T. R., Holtom, B. C., Lee, T. W., Sablyn- ski, C. J., \& Erez, M. (2001). Why people stay: Using job embeddedness to predict voluntary turnover. Academy of Management Journal, 44, 1102-1121.

Mukherjee, W. (2004, June 17). Most BPO workers change careers. The Economic Times. Retrieved October 6, 2006, from http://wwwl. economictimes.indiatimes.com/articleshow/ msid-742807.cms

NASSCOM. (2007). NASSCOMStrategic Review 2007. New Delhi: NASSCOM.

NASSCOM. (2005). NASSCOM Strategic Review 2005. New Delhi: NASSCOM.

NASSCOM. (2004). NASSCOM Strategic Review 2004. New Delhi: NASSCOM.

O'Driscoll S. (2005, November 8). BPOs bring fun back to the workplace. The Times of India. Retrieved March 10, 2007, from http://www. timesofindia.indiatimes.com/ articleshow/msid- 1288762,prtpage-I.cms

OffshoringTimes. (2005). BPOs-Those who look for a serious career. Retrieved January 9, 2007, from http://www.offshoringtimes.com/Pages/2005/BPO_news330.htm 1

O’Reilly, C. A. \& Pfeffer, J. (2000)Cisco systems: Acquiring and retaining talent in hypercompetitive markets. Human Resource Planning, 
Pandey, A., \& Singh, P. (2005). Women in call centres. Economic and Political Weekly. Retrieved February 10, 2006, from http://www.epw.org.in

Pottruck, D. S., \& Pearce, T. (2001). Clicks and mortar: Passion-driven growth in an Internet- driven world. San Francisco: Jossey-Bass. Pradhan, J. P., \& Abraham, V. (2005). Social and cultural impact of outsourcing: Emerging issues from Indian call centres. Harvard Asia Quarterly, Summer. Cambridge, MA: Harvard Asia Center.

RediffNews. (2005). Salary hike, a threat to Indian BPO. Retrieved January 25, 2007, from http:// www.rediff.com/money/2005/apr/20bpo2.htm

Remesh, B. P. (2004). Cyber Coolies' in BPO: Insecurities and vulnerabilities of non-standard work. Economic and Political Weekly. Retrieved June 20, 2006, from http://www.epw.org.in

Revathy, L. N. (2004, July 19). Live it up in office. The Hindu Business Life. Retrieved March 6, 2007, from http://www.hinduonnet.com/the hindu/thscrip/ptint.pl?fi le-2004071900040100. htm\&date=2004/07/19/\&prd=we\&

Saffold, G. S. (1988). Culture traits, strength, and organizational performance: Moving beyond "strong" culture. Academy of Management Review, 13, 546-558.

Schein, E. H. (1985). Organizational culture and leadership. San Francisco: Jossey-Bass.

Shahane, P. S. (2005, August 11). Wanna have fun sans sex? Come, join our BPO. Infotech Online. Retrieved March 10, 2007, from http:// infotech.indiatimes.com/ articleshow/msid-1197310,prtpage-I.cms

Shahane, P. S., \& Savitha, V. (2007, January 6). It's family first and tech cos and BPOs. Infotech Online. Retrieved March 11, 2007, from http:// infotech.indiatimes.com/ articlesehow/msid-1067797,prtpage-I.cms

Sheikh, Z. (2004, Nov. 1). Want a free international trip? Work for a BPO. RediffNews. Retrieved from http://in.rediff.com/getahead/2004/nov/01ga-zia.htm

Shrinate, S. (2004, June 6). Truly, a learning experience. Business Today, 156-157.

Srinivasan, T. N. (2006). Information technology and India's growth prospects. In L. Brainard \& S. M. Collins ((Ed.), Offshoring whitecollar work- the issues and implications, The Brookings Trade Forum, 2005. (pp. 203-240). Washington, DC: The Brookings Institution.

The Economic Times. (2007). How to bell the BPO cat. Retrieved March 10, 2007, from http:// economictimes.indiatimes.com/articleshow/ msid-1736650, prtpage-l.cms

The Economic Times. (2006a). BPOs' nopoaching pacts fall apart. Retrieved November 26, 2006, from http://economictimes.indiatimes. com/BPOs nopoaching pacts fall apart/ articleshow/498749.cms

The Economic Times. (2006b). BPOs get serious, axe "fun job" stage. Retrieved March 9,2007, from http://economictimes.indiatimes.com/Hot Links/ BPO/ BPOs get serious axe fun job tag/ articleshow/1486707.cms

The Economic Times. (2005). Why BPO execs are given training. Retrieved October 5, 2006, from http://www.bpo.nasscom.org/artdisplay. aspx?art_id=4491 \&cat id=608

The Economic Times. (2004). BPOs make staffers boogie woogie. Retrieved March 5, 2007, from http://www.247customer.com/newsandevents/ Article -56.php

The Times of India. (2006). Two Knights @ The Call Centre. Retrieved March 9,2006, from http:// www935.ibm.com/services/us/gbs/bus/html/ dakshnews_21 apr06.htm 1

The Tribune. (2006). Future on the line. Retrieved March 10, 2007, from http://www.tribuneindia. com/2006.20060111/jobs/mainl.htm 
Boston: Harvard Business School Press.

\section{ENDNOTES}

a. Note that the software sector is also experiencing high turnover, although not to the same extent as the BPO sector.

b. Coolie: A colonial Indian word meaning porter.

c. There is a stigma associated with women working at night. The idea of a girl staying out at night, all dressed up, and returning in the early hours of the morning looking tired raises eyebrows.

d. Even some of the "traditional" strategies noted in this chapter, e.g., providing non-job related education opportunities, do nothing to improve the nature of employees' current jobs. 